University of Nebraska - Lincoln

DigitalCommons@University of Nebraska - Lincoln

Faculty Publications from the Harold W. Manter Laboratory of Parasitology

8-1-2008

\title{
The Systematic Position of Lauroiinae Skrjabin and Schikhobalova, 1951 (Nemata: Heterakoidea: Aspidoderidae), as Revealed by the Analysis of Traits Used in Its Diagnosis
}

\author{
F. Agustin Jimenez-Ruiz \\ Southern Illinois University, Carbondale, fruiz@unlserve.unl.edu \\ Scott Lyell Gardner \\ University of Nebraska - Lincoln, slg@unl.edu \\ Dely Noronha \\ Roberto Magalhães Pinto \\ Instituto Oswaldo Cruz, rmpinto@ioc.fiocruz.br
}

Follow this and additional works at: https://digitalcommons.unl.edu/parasitologyfacpubs

Part of the Parasitology Commons

Jimenez-Ruiz, F. Agustin; Gardner, Scott Lyell; Noronha, Dely; and Magalhães Pinto, Roberto, "The Systematic Position of Lauroiinae Skrjabin and Schikhobalova, 1951 (Nemata: Heterakoidea: Aspidoderidae), as Revealed by the Analysis of Traits Used in Its Diagnosis" (2008). Faculty Publications from the Harold W. Manter Laboratory of Parasitology. 75.

https://digitalcommons.unl.edu/parasitologyfacpubs/75

This Article is brought to you for free and open access by the Parasitology, Harold W. Manter Laboratory of at DigitalCommons@University of Nebraska - Lincoln. It has been accepted for inclusion in Faculty Publications from the Harold W. Manter Laboratory of Parasitology by an authorized administrator of DigitalCommons@University of Nebraska - Lincoln. 
Published in Cladistics, vol. 24, issue 4 (Jan. 2008): 459-476. doi: 10.1111/j.1096-0031.2007.00194.x.

Copyright 2008, the Willi Hennig Society and Wiley/Blackwell.

http://www.interscience.wiley.com/jpages/0748-3007. Used by permission.

\title{
The Systematic Position of Lauroiinae Skrjabin and Schikhobalova, 1951 (Nemata: Heterakoidea: Aspidoderidae), as Revealed by the Analysis of Traits Used in Its Diagnosis
}

\author{
F. Agustín Jiménez-Ruiz ${ }^{* a}$, Scott L. Gardner ${ }^{\mathrm{a}}$, Dely Noronha ${ }^{\mathrm{b}}$ \\ and Roberto Magalhães Pinto ${ }^{b}$ \\ a The Harold W. Manter Laboratory of Parasitology, University of Nebraska State Museum, \\ Lincoln, NE 68588-0514, USA \\ ${ }^{\mathrm{b}}$ Laboratório de Helmintos Parasitos de Vertebrados, Instituto Oswaldo Cruz-Fiocruz, \\ Avenida Brasil 43565, 21040-900 Rio de Janeiro, RJ, Brazil \\ Send correspondence to: * fruiz@unlserve.unl.edu.
}

Manuscript accepted October 2, 2007.

\begin{abstract}
During our work on biodiversity of parasites of mammals of the Neotropics we collected numerous nematodes assignable to species of the family Aspidoderidae (Nemata: Heterakoidea). These nematodes occur as parasites of the cecum and large intestine of marsupials, rodents and xenarthrans (armadillos) only in the New World. As aspidoderid nematodes have been little studied beyond their alpha taxonomy, it is the purpose of the present paper to apply phylogenetic systematic methods to more completely understand the evolutionary relationships of the included species. Members of the aspidoderid subfamily Lauroiinae have had very little work applied to their systematic relationships and no systematic revisions exist that include all recognized species. Diagnostic characters that define species in this subfamily include plate-like cuticular structures on the anterior end. Herein we define a suite of 52 characters derived from studies of specimens using both light and electron microscopy. Our phylogenetic systematic analysis included the eight known species in the Lauroiinae, seven of the Aspidoderinae and four outgroup taxa. The results indicate that the Lauroiinae is paraphyletic, that the cephalic plates on the anterior end are not synapomorphies for the Lauroiinae, and that structures forming the cordon are present in all species of the family. We propose elimination of the subfamily designations in the family Aspidoderidae and we show the utility of using additional characters in the diagnosis of the family and the genera within this family. The resulting hypothesis should serve as the foundation to understand the historical associations of the nematodes with the mammals they infect.
\end{abstract}

The Aspidoderidae Skrjabin \& Schikhobalova, 1947 (Ascaridida: Heterakoidea) currently includes 17 species divided among four genera. The worms occur in the cecum and large intestine of mammals with distributions restricted to southern Nearctic and general Neotropical regions. The known host range for species in the family includes xenarthrans, didelphiomorphs (i.e., New World marsupials), and hystricognath and sigmodontine rodents.

Nematodes classified in the Aspidoderidae Skrjabin \& Schikhobalova, 1947 include species allocated to the subfamilies Aspidoderinae Skrjabin \& Schikhobalova, 1947 and Lauroiinae Skrjabin \& Schikhobalova,
1951. Most taxonomic revisions that have been conducted on this family have focused on Aspidoderinae (Proença, 1937; Vicente, 1966; Santos et al., 1990), which includes one genus, most of the species in the family (nine), and there are numerous collection records across the Americas (Vicente et al., 1997). The subfamily Lauroiinae Skrjabin \& Schikhobalova, 1951 was included in the family Aspidoderidae by Inglis (1957a), based on the presence of shield-like structures on the anterior end of individuals allocated to species of both Lauroia Proença, 1938, and Paraspidodera Travassos (1914). Using the same criterion, species of the genus Nematomystes Sutton, Durette-Desset \& Cha- 
baud, 1980, were included in the subfamily Lauroiinae (Sutton et al., 1980). At the time neither the species nor the characters of the Lauroiinae were as well known as those of the Aspidoderinae.

Species included in the Lauroiinae occur in the cecum and large intestine of New World xenarthrans (armadillos), geomyid, hystricognath (pacas and agouties), and sigmodontine rodents. The subfamily includes eight species allocated into four genera.

The subfamily Lauroiinae is diagnosed by "cephalic cordons lacking; lateral lobes of lips simple" (Inglis, 1957a, 1967; Chabaud, 1978). The wording of this diagnosis describes the overall appearance of structures at the anterior end and surrounding the oral opening and it leaves room to include a great variety of specimens with overall similarity (Figure 1). This con- trasts with the diagnosis used for members of the Aspidoderinae, which includes the presence of cordons with recurrent branches (Chabaud, 1978) (Figure 1). However, in both groups the cuticle arising from the posterior extremes of the surface of these plates forms a small flap (Figure 1). That flap covers a groove and together those structures are named the "cordon", a term coined by Inglis $(1957 a, b)$ who studied the anatomy of the anterior end of members of the cosmopolitan superfamily Heterakoidea.

Thus, current knowledge of members of the family is biased, based only on a subset of taxa, and the overall character set of morphological features presently used to define that subset is limited. It is the aim of the present paper to: (1) test the monophyly of Lauroiinae; (2) evaluate the characters used in the diagno-

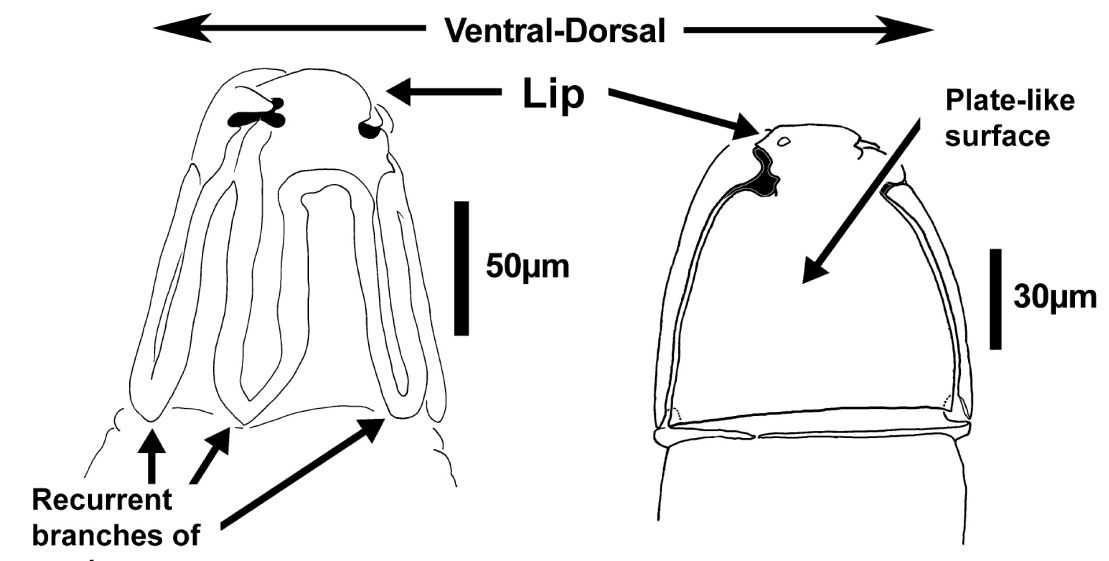

cordons

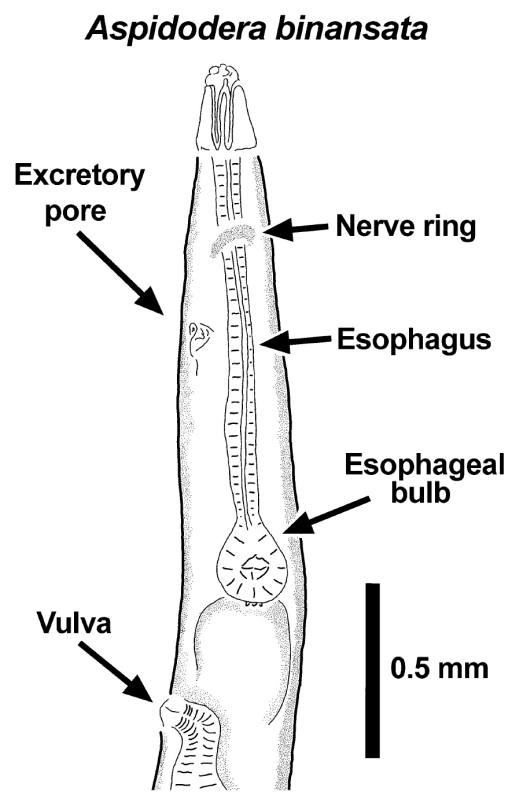

Lauroia trinidadensis

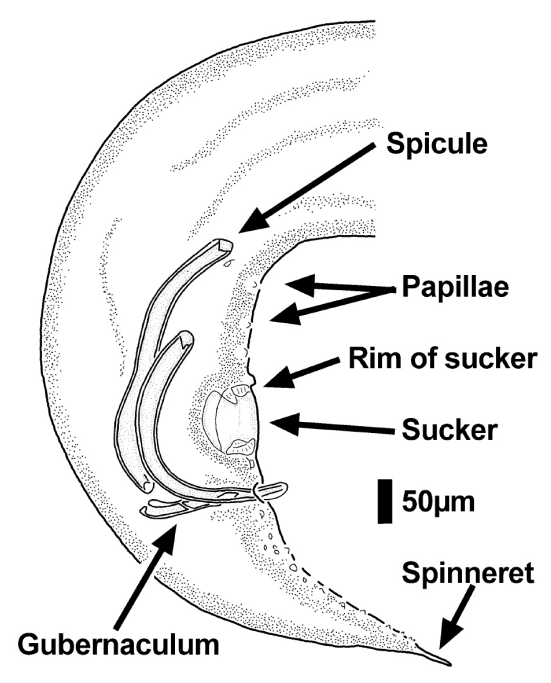

A. sogandaresi female

A. sogandaresi male

Figure 1. Examples of the structures of the hood in Aspidoderidae as seen in the right lip. Internal organs of aspidoderid nematodes used as characters. 
sis of the group; and (3) clarify the relationships of the species included in the Lauroiinae with other species in the family. In addition, we use the resulting phylogeny to review the characters that are useful for classification of these interesting nematodes.

\section{Materials and methods}

We studied material derived from museum collections and from specimens we obtained during field-work in both the Neotropical and southern Nearctic regions. Appendix 1 includes the names and acronyms of the museums that provided comparative material.

For transmitted light microscopy using Normarsky or bright field methods, specimens were cleared with lactophenol. Species were identified using published descriptions and by direct comparison with type and voucher specimens. Specimens prepared for scanning electron microscopy (SEM) were treated using the osmium-thiocarbohydrazide-osmium-thiocarbohydrazide-osmium (OTOTO) method, dehydrated, dried by critical point drying using $\mathrm{CO}_{2}$, and then sputter coated with gold-palladium. Specimens mounted on temporary slides were studied with a Zeiss ${ }^{\mathrm{TM}}$ ultraphot microscope. Images produced by SEM were created by exposing specimens to an electron beam of 15 $\mathrm{kV}$ on a Hitachi ${ }^{\mathrm{TM}}$ field S-2500 and S-3000.

Morphological characters included in the data set were collected by observing adult worms mounted on temporary slides and on stubs for scanning electron microscopy. We selected some traits as characters when it was possible to propose that two or more distinct features were homologous (Platnick, 1979). To separate character states we coded the shapes as mutually exclusive in a multistate matrix.

Our analysis includes 38 characters that are present in both sexes and 14 that are linked to the sexual organs or to secondary sexual traits. In Aspidoderidae, most sexually dimorphic characters are associated with the reproductive system (e.g., genital papillae on the tail of males), with few secondary sexually dimorphic characteristics that are visible. With the exception of size, the only dimorphic character that we could identify in these nematodes is the shape of the tail at the posterior end, which tapers gradually towards the end of the body in the females and having three alternative shapes in males. From the structures that we found to be phylogenetically useful characters, 11 had been used previously to diagnose species in the family (Freitas, 1956; Inglis, 1957a,b; Chabaud, 1978; Proença, 1937; Vicente, 1966; Santos et al., 1990) and include character numbers $3,4,5,7,9,10,14,15,19,26$ and 27 as indicated in results.

Twenty-nine characters are visible with light microscopy and from that number, 19 are present in both sexes. For this study, the number of observations equals the to- tal number of specimens that we mounted for observation on temporary slides, which averaged 20 specimens per lot. A lot represents one species of parasite collected from an individual host. The observations on characters linked to sex were usually half the total number of specimens available for each species. A reduced sample size was available for 23 characters that could only be seen by either sectioning of specimens or the use of SEM to establish the state of character. For these characters we were able to section just two specimens and to prepare two to four specimens for SEM per species.

In summary, characters 2, 4-12, 19, 23-26, 28, 29, 31, 38 and 44 are easily seen with light microscopy and are present in both sexes; characters 14-25, 27 and 36 are linked to sexual structures, of which only character 19 is from females. Finally, characters 1, 3, 30, 32, 34, 35, 37, $39,40-43$ and $46-52$ are seen only by sectioning specimens (characters 1 and 3) or with the use of SEM.

Criteria for selection of outgroups was taxonomic proximity; the four taxa selected are members of the superfamily Heterakoidea and they are included in the Heterakidae (Chabaud, 1978). Characters studied were analyzed for phylogenetic signal using parsimony as implemented in PAUP* 4.10 (Swofford, 2003).

For analysis of the data set we had access to all species in the family except Aspidodera subulata (Molin, 1860) for which it was not possible to process specimens for SEM; the matrix for this data set with 52 characters coded for 15 species and four outgroup taxa, is shown in Table 1. Lauroia intermedia Caballero, 1955 was excluded from the matrix because the diagnostic character that makes it conspicuously different from L. trinidadensis is a single autapomorphy.

Several morphological features are defined relative to the dorsoventral plane of the body of these nematodes and this plane may be divided into three axes. The dorsal aspect occupies most of the dorsal half (lips labeled as 1 in Figure 2), whereas the ventral aspect of the body may be divided into two lateral parts (labeled as 2 and 3 in Figure 2). The right side has the right ventral lip (labeled as 3 in Figure 2), which will be referred as the dextroventral lip; similarly the left lip will be referred to as the sinistroventral lip (labeled as 2 in Figure 2).

The data set was analyzed using parsimony as the optimality criterion with all multistate characters treated as unordered and unavailable character states treated as missing. The most parsimonious trees were determined by branch-and-bound, computing the initial upper bound by stepwise addition and performing simple addition sequence, saving only the best trees. For tests of robustness we calculated both jackknife and the Bremer support index (Bremer, 1988) for each clade. The latter was calculated using TreeRot versus 2c (Sorenson, 1999), and by calculating the difference 
Table 1. Matrix of morphological characters coded for Aspidoderidae and four outgroups.

\begin{tabular}{|c|c|c|c|c|c|c|}
\hline Taxa & 0 & 1 & 2 & 3 & 4 & 5 \\
\hline & 123456789 & 0123456789 & 0123456789 & 0123456789 & 0123456789 & 012 \\
\hline Heterakis gallinarum & $00 ? ? 000 ? ?$ & ???1102010 & 0101000010 & 2111000100 & ??01011010 & 001 \\
\hline Odonterakis sp. & 100010110 & 1011102010 & 0001000010 & 2110000110 & ??01011010 & 001 \\
\hline Strongyluris similis & $00 ? ? 0000 ?$ & ??11102010 & 0001001110 & $0 ? 1 ? 0 ? ? ? ? ?$ & ????011000 & 001 \\
\hline Lauroia bolivari & 100010000 & $011001 ? 111$ & 0111000000 & 0110000110 & 1001011011 & 101 \\
\hline Lauroia trinidadensis & 100010011 & $100001 ? 111$ & 0111000000 & 0110000110 & 1001011011 & 101 \\
\hline Proencaia heterospiculata & 100011011 & $100011011 ?$ & 0110000000 & 0000110000 & 1001011001 & 101 \\
\hline Paraspidodera uncinata & 110011000 & 0111102100 & 1010111110 & 0001111011 & 0110000101 & 110 \\
\hline Nematomystes rodentophilus & 111110100 & 1111102101 & 1010011011 & 0110010010 & 1001111011 & 101 \\
\hline Aspidodera binansata & 111111111 & 1101102100 & 1010010001 & 1001111000 & 0110000011 & 110 \\
\hline Aspidodera fasciata & 111111111 & 1121102100 & 1010110010 & 1001111001 & 0110001001 & 110 \\
\hline Aspidodera vazi & 111111111 & 0121102100 & 10101101?? & 0110110000 & 0100000111 & 110 \\
\hline Aspidodera lacombae & 111111111 & 1021102100 & 1010010010 & 1100011001 & 1011101001 & 110 \\
\hline Aspidodera scoleciformis & 110011111 & 1000102100 & 1000010101 & 1001111001 & 0110000001 & 110 \\
\hline Aspidodera ansirupta & 110011110 & 1000101100 & 1010010000 & 0001111001 & 0110000001 & 110 \\
\hline Aspidodera sogandaresi & 111111111 & 1122101100 & $10101101 ? ?$ & 0100110000 & 0110001111 & 110 \\
\hline
\end{tabular}

Figure 2. En face view of four species of Aspidoderidae showing the positions of the lips. Dorsal lip is labeled 1 in all images; ventral side includes two lateroventral lips labeled as 2 (sinistroventral) and 3 (dextroventral). Aspidodera scoleciformis (i), A. bolivari (ii), A. scapteromi (iii), and P. uncinata (iv).

between suboptimal trees and the optimal or shortest tree, associating an integer to the clade in which a given clade was collapsed. Estimation of jackknife value was based on 1000 replicates with $32.7 \%$ of de- letion of the data, with a branch and bound search using PAUP* (Swofford, 2003).

A tree enforcing the monophyly of both Aspidoderinae and Lauroiinae, and trees enforcing the mono- 
phyly of Lauroia and Aspidodera were constructed and analyzed using the settings explained above. The results were compared with the shortest optimal tree.

\section{Results}

\section{Characters and character states}

1 Size of dorsal lip with respect to both lateroventral lips. Width of dorsal lip equal to both lateroventrals (0); dorsal lip wider than lateroventrals, occupying most of dorsal half (1). To code the state of this character it was necessary to observe the anterior end en face, thus sectioning of the specimens was necessary and the number of specimens observed per species is moderately low (six on average). Dorsal lip is 1 in Figure 2.

2 Postlabial cuticle (plates/body engagement) $\mathrm{Cu}-$ ticle smooth (0); cuticle arises from body (1). Cuticle may form plates behind lips, with muscles associated with each. This character is conspicuous and most of the times visible with the naked eye, the number of observations depended on the number of specimens available for study.

3 Shape of dorsal plate. Rectangular (0); trapezoidal (1). Dorsal plate has varying forms that are independent of lateroventral plates. In a rectangular plate both base and top are of the same width; in a trapezoidal plate, the base is wider than the top (see Figure 3).

4 Shape of lateroventral plates. Rectangular (0); triangular (1). The rectangular shape consists of a plate that is homogeneous along its entire length, so width of base and top are similar. In the triangular shape, the top is conspicuously narrower than base, matching a narrow lip (Figure 4).

5 Cuticular expansion of anterior end (hood). Cuticular expansion that forms hood not separated from rest of body (0); hood separated from body by a thick fold (1). The formation of the hood on the anterior end of the body is not an exclusive feature of Aspidoderidae. It also occurs in other species of Heterakoidea and consists of a "thickening" of cuticle on the ante-
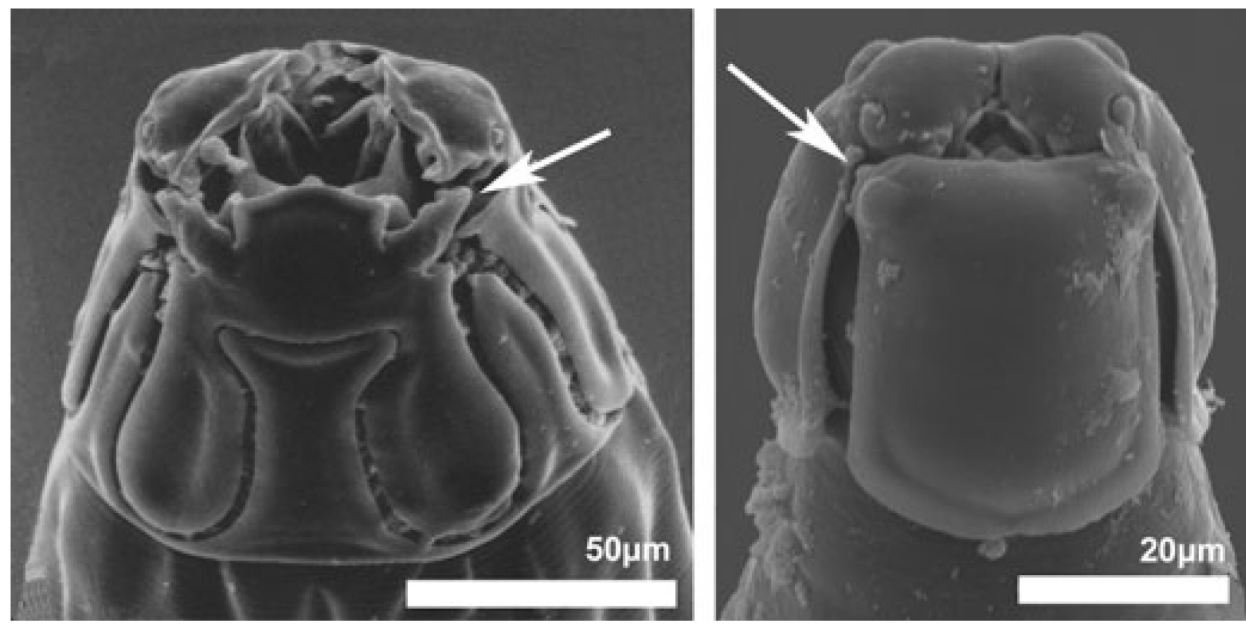

Figure 3. Shape of the dorsal plate in two species of aspidoderid nematodes, character 3, Contrast the trapezoid shape of $A$. scoleciformis (left) with the rectangular shape of L. bolivari (right). Arrows indicate digitiform projection (character 6) in the top of anterior end.
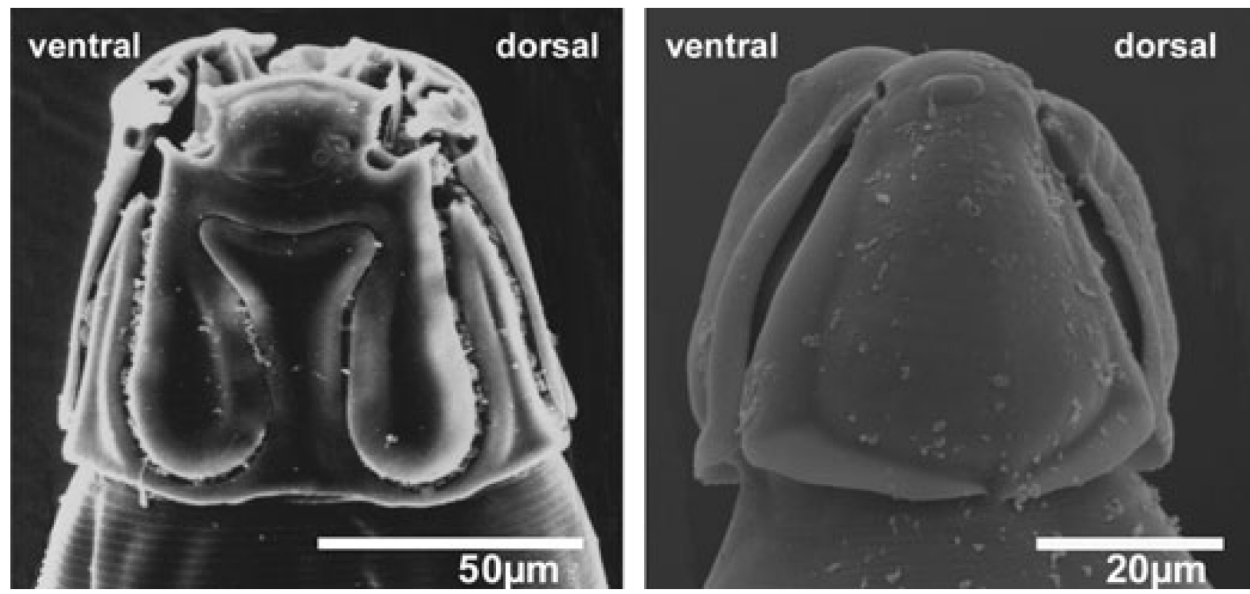

Figure 4. Shape of sinistral (left) plates in A. scoleciformis (left) and L. bolivari (right); character 4. 
rior end. This thickening consists of a muscular structure that arises from the body, giving the expanded anterior end the appearance of being separated from the rest of the body and is distinguishable even when the muscles are relaxed. Structures described for characters 3,4 and 5 can be observed and coded by rolling the specimens mounted on temporary slides, usually an average of 20 specimens per lot.

6 Projections of dorsal lip. Dorsal lip blunt, barely protruding from body (0); digitiform (1). Dorsal lip has lateral projections that emerge from the middle and often bear dorsal sessile papillae. These projections are poorly developed in some species, appearing only as bumps on cuticle of lip. In other cases they are present as well developed digitiform extensions that emerge from the lip. State of character 1 is indicated with an arrow in A. scoleciformis (Figure 3); character state 0 is indicated with an arrow in L. bolivari (Figure 3). Characters 6-12 can be easily seen in specimens mounted on temporary slides, for this character, we observed up to 20 specimens per lot.

7 Interlabial space (development of interlabium). Simple free space between plates (Atrophied) (0); cuticle arises to separate both plates (connected to interlabial intrusions) (1). The interlabium and its importance in the systematics of the Heterakoidea were discussed thoroughly by Inglis (1957b). This structure is a piece of cuticle and muscle that arises from the body and separates the plates; it develops as a digitiform piece between the plates in some species, whereas in others it remains as a simple space between the plates.

8 Cuticle in the interlabial space (interlabial velum). Cuticle tightly attached to body (0); cuticle loose forming a flange (1). The cuticle arises from the interlabial structure and covers the space between the plates, this structure has been referred to as the velum (see arrows in Figure 5).

9 The space between the plates and the body forms a groove. Labial grooves restricted to the interlabial space (0); or continuous connecting each of the interlabial spaces (1). This groove is sometimes continuous forming structures called "cordons" (Inglis, 1957b; Chabaud, 1978). Examples include A. scoleciformis in Figs 3 and 4, and A. lacombae and A. raillieti in Figure 5. In other species the groove is present only as a space between the lips or plates (L. bolivari and P. uncinata in Figs 4 and 5).

10 Cordon outline or margins of the groove. This refers to the apparent constrictions present in the cordons found in the anterior end of the body. The state
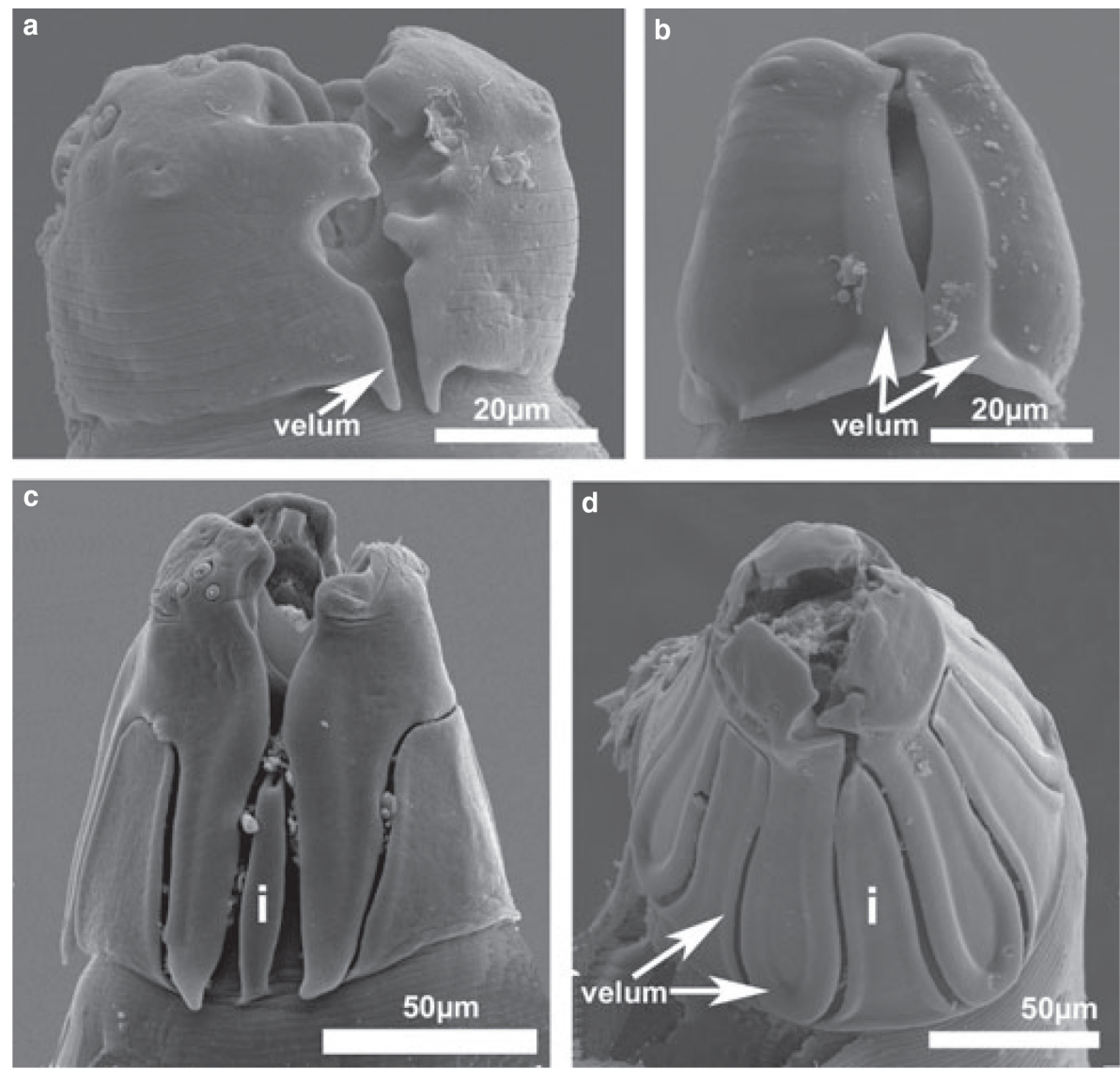

Figure 5. Detail of the space between two plates in the hood of four species of Aspidoderidae. Arrows indicate interlabial and labial velum (superior and inferior arrows, respectively). Interlabium is labeled with an "i." Paraspidodera uncinata (a), L. bolivari (b), A. raillieti (c), and A. lacombae (d). 
irregular (0) indicates that the groove or margin of the cordon is not uniform along its length, narrowing conspicuously at various points; alternative state (1) indicates a regular and uniform groove along its entire length.

11 Cephalic plate space. Open space between cephalic plates (opening of cordons) not formed (0); or formed (1). In the interlabial spaces the plates may be free, forming an open space between the structures, with alate protrusions arising from the posterior corners of each plate. The alternative state refers to a $\mathrm{cu}$ ticular outgrowth of the interlabium that closes such a space.

12 Position of pharynx-esophagus junction. Three states observed: posterior limit of hood matches pharynx-esophagus junction (0); posterior limit of hood is shorter than the pharynx-esophagus junction (1); posterior limit of hood is longer than the pharynx-esophagus junction (2). This character refers to the size of the hood with the pharynx size representing a consistent landmark relative to the size and posteriad extent of the hood. The size of this structure is a diagnostic feature for several species in the family. These character states were coded using light microscopy as the pharynx is an internal structure; therefore, character state 1 was difficult to code as in several specimens the hood can be too short or too long for observation of the junction of the pharynx-esophagus.

13 Transverse outline of lateral alae. Alae rounded (0); acute (1); or smooth (2). Lateral alae are structures present on both sides of the body; each is formed by a hypodermal cord below the cuticle and is manifested as a ridge-like structure on the surface of the body. In some cases the alae are not visible externally as the cuticle does not rise from the body, in this instance it is referred to it as "alae smooth." Character states are shown in Figure 6. The states of this character can only be seen via sectioning specimens, so this character was observed in two to four specimens per lot.

14 Precloacal cuticle of males. Entirely smooth (0); or provided with a rim surrounding sucker (1). Male heterakoids posses a sucker on the precloacal ventral surface that is usually surrounded by a conspicuous cuticular rim, not present in some taxa. States illustrated in Figure 7. Character exclusively in males, observable in any complete specimen even with the naked eye.

15 Postcloacal cuticle of males. Males have several papillae on the ventral surface of tail some with a characteristic medial bump. Thus the medial space of the ventral cuticle is referred to as postcloacal ornamentation of males, which may be entirely smooth (0); or with a medial bump (1) see Figure 7.

16 Papillae associated with caudal sucker. Number of papillae variable between species and in most cases these papillae are found at the posterior edge of the rim of the sucker. There are species with no papillae (0); a single medial (1); or a single medial and two smaller submedial (2). We studied fewer than four specimens per species because this is visible only via SEM.

17 Genital papillae of males. Pedunculate (0); or sessile (1). Heterakoid nematodes usually have numerous caudal papillae, which can be either sessile or pedunculate. The presence of sessile caudal papillae was once considered a diagnostic character in early classifications (Skrjabin et al., 1961; Inglis, 1967). The character was proposed based on observations made of all males, as shape of papillae is clearly conspicuous.

18 Precloacal papillae of males. Precloacal papillae of males arranged as 1st pair lateroventral and 2nd and 3rd pairs subventral (0); all three pairs in a subventral row (1). Papillae variable in number; however, three pairs of papillae are constant for most taxa. In particular, pairs 2 and 3 (closest to cloaca) occur in two subventral rows. The first pair is characteristic because for some groups it is aligned with the other pairs; while in other groups that pair is more laterally oriented than pairs 2 and 3 . As character 16, the arrangement of the spicules can only be detected when specimens in ventral view are available (Figure 8 ).

19 Position of vulva. Vulva located in middle of body (0); or in last third of body (1). "Middle of body" refers to vulva opening on the line that divides the
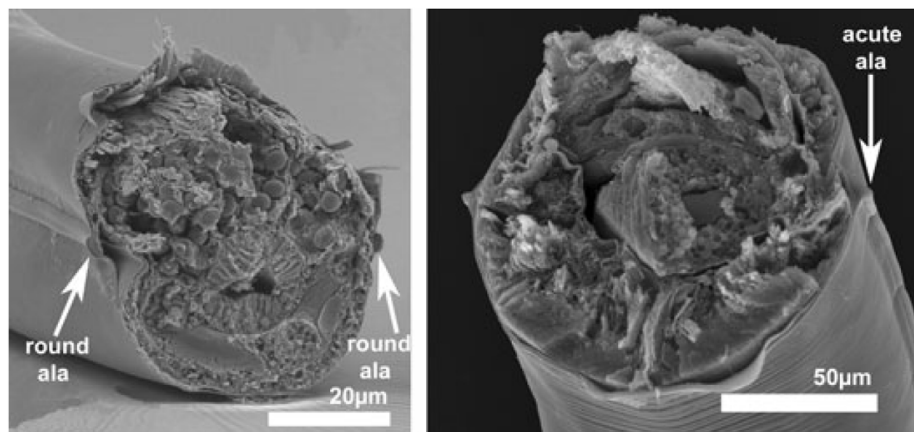

Figure 6. Cross-sections of A. lacombae (left) and A. vazi (right) showing two states of character for the outline of the lateral alae. 

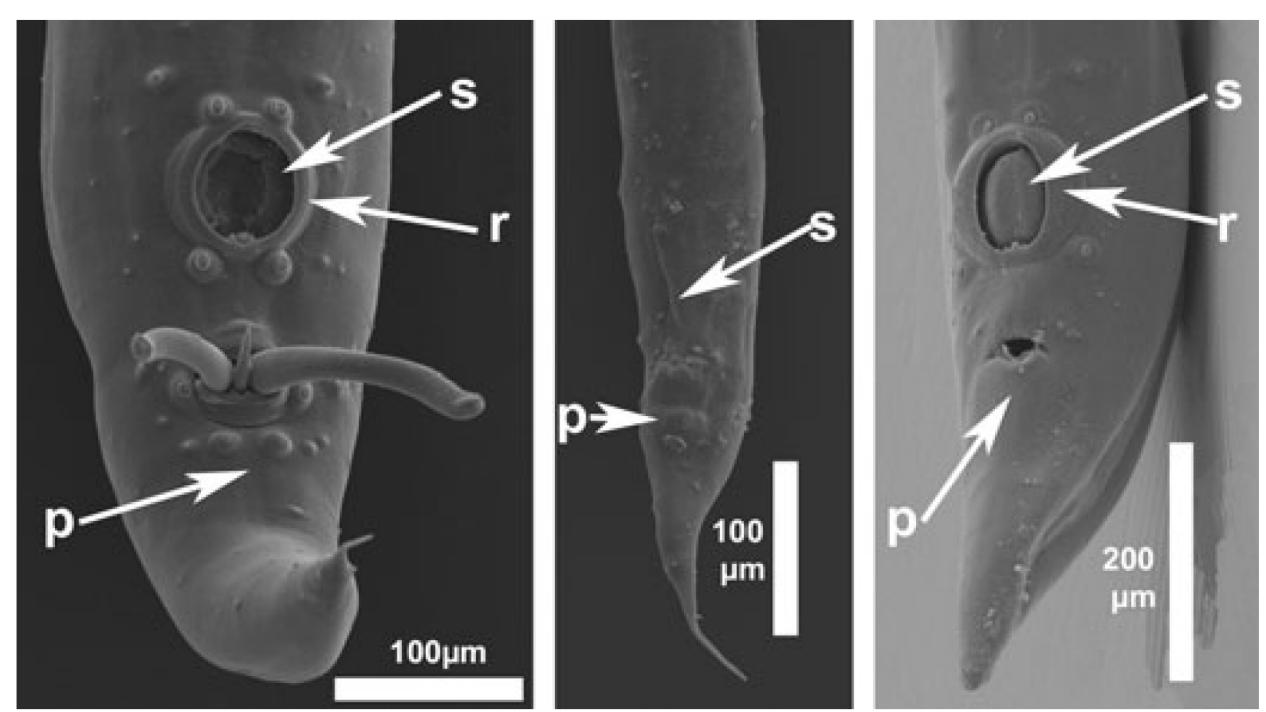

Figure 7. Ventral surface of the tail of A. raillieti (left image), L. bolivari (centre), and A. lacombae (right). Note the sucker(s) surrounded by a cuticular rim (r), in A. raillieti and A. lacombae; contrast them with the sucker with no rim (s) and a conspicuous postcloacal bump (p) in L. bolivari.
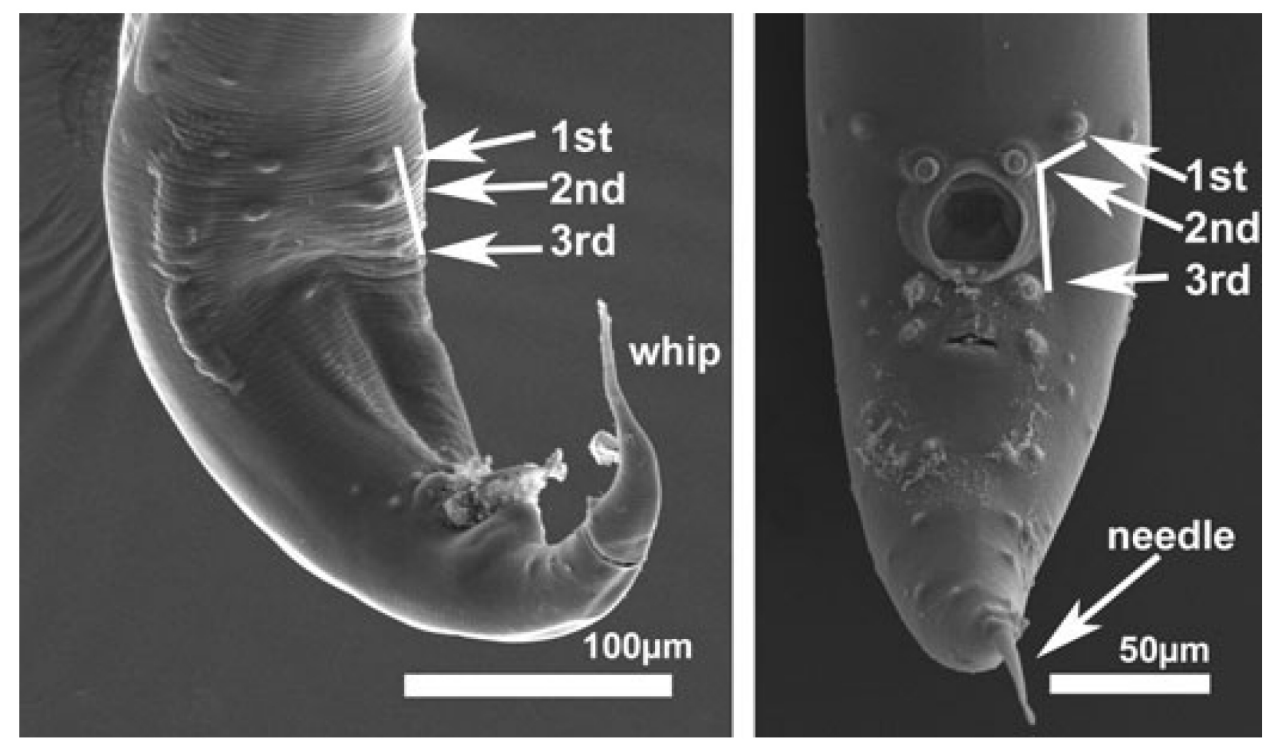

Figure 8. Caudal end of L. trinidadensis (left) and A. raillieti (right), showing the disposition of the precloacal papillae with a white line. Note the sucker with no rim and the filiform spinneret in the former, and the needle-shaped spinneret in the latter.

body in two halves. "Vulva in the last third of body" (1) indicates that the opening of the vulva is closer to the tail. This character occurs only in females and can be coded and observed on all complete specimens mounted on temporary slides or on stubs for SEM.

20 Dorsal wall of spicular pouch may form a gubernacular mass (0); or it may be developed to a well cuticularized gubernaculum (1). This structure occurs only in males and is easily visualized with light microscopy.

21 Length ratio of spicules. Spicules equal in size (0); or unequal in size (1). This character has been historically important in the taxonomy of the family because it is non-variable at the intraspecific level; however, there are some species (e.g., Heterakis gallinarum) for which there is considerable variation at the intraspecific level (Inglis, 1967, 1991; Inglis et al., 1971). Nevertheless, the structure is consistent at the interspecific level in all the species of the family.

22 Texture of the surface of the spicules. This character, observed with SEM shows the spicules with either a smooth surface (0); or granular rough ornamentation (1). An example of rough versus smooth surfaces is seen in Figure 9 for A. ansirupta and A. vazi, respectively. For this character, only one or two males per species were studied as all observations were via SEM.

23 Shape of distal end of spicules. Spicule tips blunt (0); or sharp (1). The tips of the spicules differ among species; either the distal spicule tip is acute and narrows 

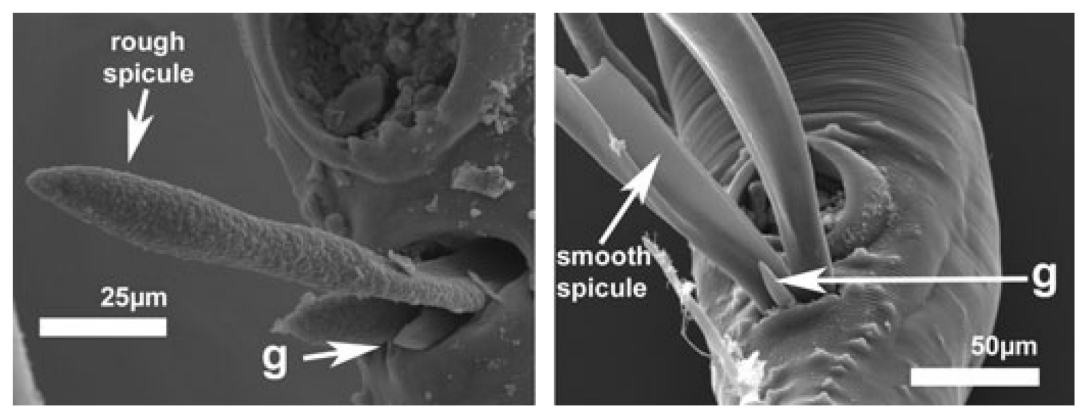

Figure 9. Surface of the spicules of A. ansirupta (left) and A. vazi (right) contrasting the rough and smooth surface of spicules. In both micrographs the distal end of the gubernaculum $(\mathrm{g})$ is visible. to a sharp tip, or the tip of the spicule is blunt (e.g., Aspidodera). This structure is visible with light microscopy.

24Overall shape of spicules. Spicules straight (0); fusiform (1). In Aspidoderidae, spicules vary in thickness and lengths providing a diagnostic shape for each species. The shorter the spicules the wider the calomus, so the appearance of the structure is fusiform, with a wide lamina. The long spicules have both a narrow calomus and narrow laminae that make them appear straight.

25 Cuticular thickness of spicule. Thin wall and outgrowth on tip absent (0); or thick wall and outgrowth on tip present (1). This character is seen clearly as an outgrowth on the tips of the spicules; in species having a thick walled spicule the outgrowth is quite evident.

26 Shape of esophageal bulb. Bulb spherical (0); or bulb claviform (1). The esophageal bulb in heterakoid nematodes is tri-valved and connected to the intestine. In most species in the superfamily the structure is spherical; however, in some species the longitudinal axis is longer than the transverse axis (i.e., Paraspidodera uncinata, Nematomystes spp.).

27 Tail of males. Tip of the tail of males filiform, loose at the basal portion extending posteriad as a long structure (0); needle-shaped, structure not loose in basal portion and relatively short in extension (1).

The tail ends in a sharp structure formed mainly by cuticle; this may be long and smoothly tapered or short and sharp. See Figure 8.

28 Origin of lateral alae. Alae arising at level of the nerve ring (0); or alae arising just behind the hood (1) (always anterior to the nerve ring). The origin of these structures is from cuticle arising from the sides of the body, forming a continuous and uniform ridge.

29 Posterior termination of lateral alae. Alae terminate in region of tail (0); or alae terminate in posterior third quarter of body (1). In several species, the latter would match with the vulva, coding this character is possible for all specimens observed.

30 Sockets inside dorsal lip. Number of sockets present, either one pair (0); or sockets present in a double pair (1) (Figure 10). In this case, the fossets in the inner surface of the dorsal lip match the digitiform structures present in the lateroventral lips, which enable the stoma to close tightly. These structures as well as others in the stoma are better seen with SEM, as they are difficult to distinguish with light microscopy.

31 Cuticular extensions of dorsal plate. In the dorsal plate, the thin cuticle forms a velum that is either attached to a digitiform projection that is perpendicular to the margin of the plate (0); or to the basis of the lip (1).
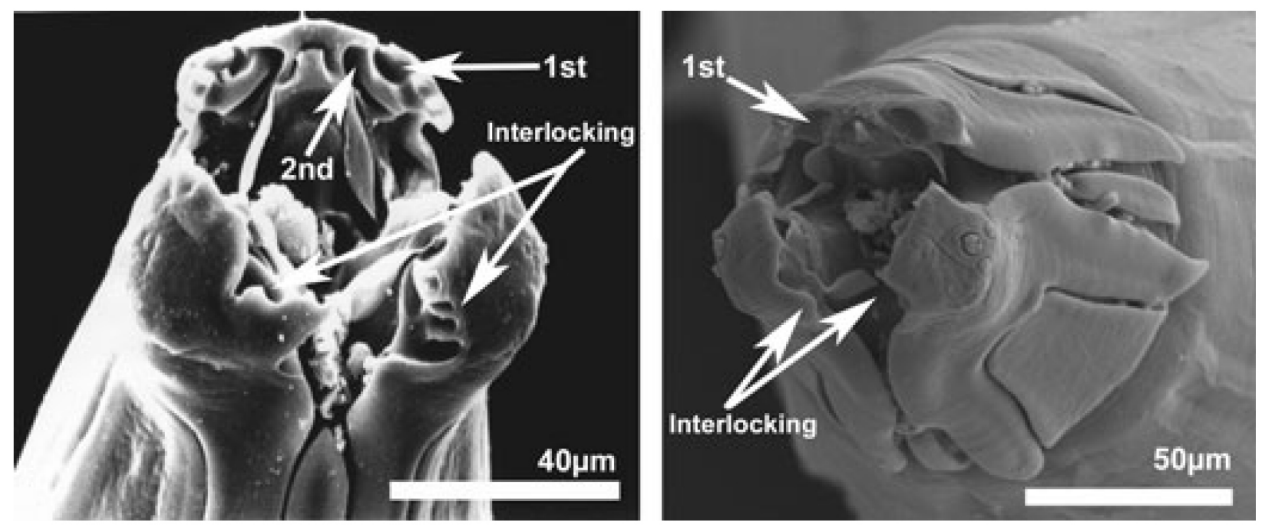

Figure 10. Sockets associated with the stoma in two species of Aspidoderidae. Note the double pair of sockets in A. fasciata (left) and the single pair of sockets in $A$. raillieti (right). 
32 Notches in top of dorsal lip. Frontal notches in the dorsal lip are deep (less than $90^{\circ}$ ) (0); shallow (more than $90^{\circ}$ ) (1). This character is associated with the presence of a medial flange and refers to notches that separate the digitiform structures and the flap. However, the depth of this notch refers to the angle of the digitiform structures with respect the longitudinal axis of the body. This character can be evaluated using light microscopy, although SEM helps to clearly determine the state of character.

33 Degree of ventral inflection of dextroventral lip. Ventral inflection in ventral side of dextroventral lip less than $90^{\circ}(0)$; more than $90^{\circ}(1)$. The presence of a digitiform structure at the base of this lip and the ventral margin of the lip form an inflection that presents different degrees of infolding. See Figure 2 in which A. scoleciformis and L. bolivari, respectively, match this character.

34 Projection on ventral side of sinistroventral plate. Projection blunt, not arising from the body (0); or digitiform (1). This projection is part of the interlocking system of the lips (Inglis, 1957b), which is formed by the sinsitroventral plate and a corresponding depression in the dextroventral plate. This works as a dovetail that allows the stoma to be closed. Characters 3436 can only be observed using SEM.

35 Dorsal projection sinistroventral plate. Outgrowth from dorsal side of sinistroventral plate projecting towards the dorsal lip in which the structure is in the base of the sinistroventral lip and may be bulky and wide (0); or it may protrude as a digitiform piece (1).

36 Ornamentation on lateral projections of dorsal lip. Ornamentation simple or smooth (0); or serrated (1). The cuticle of the anterior surface of the structures may present two different kinds of ornamentation; their complexity is correlated with the structures found on the dorsal sides of the lateroventral plates.

37 Apical portion of dorsal lip. Flange extends toward stoma (0); dorsal lip with a homogeneous surface (1). The apical portion of the dorsal lip may form a flange that extends forward; the flange is produced by the presence of two submedial indentations or notches that divide the dorsal lip in three parts. The latter is present in most of the members of the superfamily, so the former may be considered an exclusive structure for Aspidoderidae, missing in some species. See Figure 2.

38 Velum on dorsal side of lateroventral plates. Velum extending forming ventrolateral plates. Dorsal side may be either attached to a digitiform projection (0); or attached to side of lip (1).

39Dorsal margin of dextroventral lip. Cuticle of dorsal side of dextroventral lip may have one of two kinds of ornamentation, asmoothsurface(0);oraserratedsurface(1).

40 Direction of horn-like projections of dorsal lip.
Notches dividing dorsal lip in three parts, leaf-shaped structures directed to the sides of the plate (0); or directed towards the stoma (1).

41 Shape of horn-like projections on lips. Horn-like projections massive blunt structures (0); or acute projections oriented anteriad from the lip (1).

42 Degree of smoothness of upper margin on ventral side of sinistroventral lip. Margin smooth (0); or serrated (1). Described by Inglis (1957b) as "the interlocking" portion on ventral side of the sinistroventral lip receiving an extruded projection arising from the ventral margin of the dextroventral plate.

43 Degree of inflection of the ventral upper margin of sinistroventral lip. Structures formed by ventral finger-like projection on ventral side of sinistroventral lip forming either an angle of $90^{\circ}$ with respect to the plate (0); or an angle greater than $90^{\circ}(1)$. This interlocking portion divides the lip from the plate; in some species structure does not emerge from cuticle.

44 Arrangement of papillae in ventral lips. Character multistate, coded as two marginal papillae (0); two marginal papillae and one exterior (1); or three marginal papillae (2). All species of heterakoids possess two sessile papillae on the dorsal side of both lateroventral lips. Some species posses a third sessile papilla the position of which is variable depending on the species. Labial papillae are easily seen with light microscopy.

45 Dorsal corner of dextroventral lip or massiveness and width of end of dextroventral lip. Two states of character, offset from the lip (0) appearing to be wider in the top as if corners were expanded; or apical part with same width in the basis than in top (1). This structure is best imaged with SEM (Figure 11) although the determination of the states of character can be done using light microscopy.

46 Occlusion of dorsal corner of dextroventral lip. Conspicuous projection, digitiform (0); or smooth ornamentation (1). Each flank of dextroventral lip provided with cuticular structures that arise from the lip forming projections.

47 Occlusion of ventral corner of dextroventral lip. Blunt structures barely arising from cuticle (0); or finger-like projections emerging from cuticle (1).

48 Number of projections or bumps in horn-likestructures on dorsal lip; these cuticular structures are constant in number. One projection (0); or two projections (1).

49 Relative size of cheilorhabdia. The cheilostome is formed by three cuticular flanges, each matching a lip (Figure 12). Each of these flanges is a cheilorhabdion. The cheilorhabdion may exceed the margins of the lips as if projecting anteriad (0); or it may be entirely included inside the margins of the lip (1). 

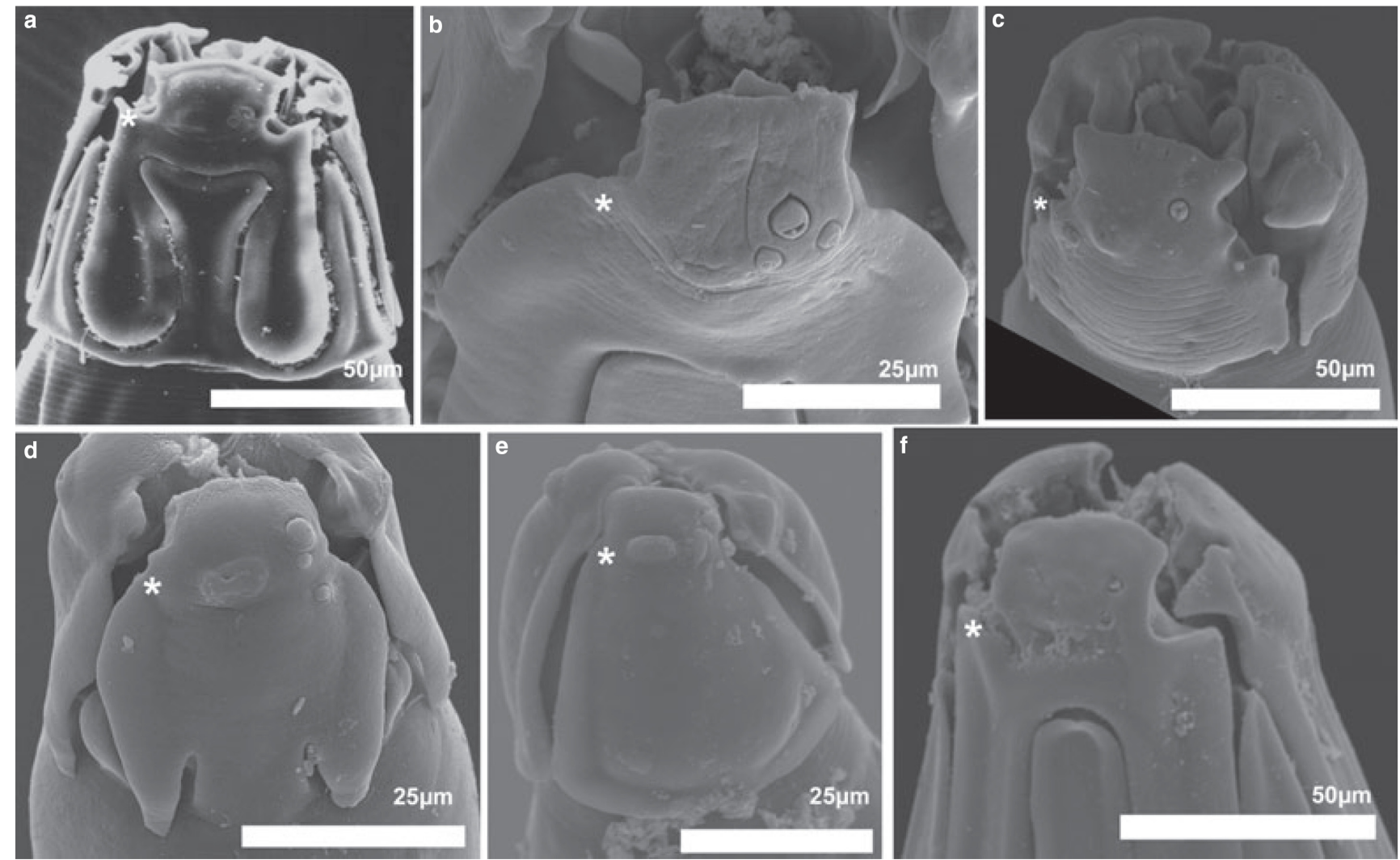

Figure 11. Papillae on the sinistroventral lips of six species of Aspidoderidae (character 44). Note three papillae in A. raillieti and N. scapteromi. The asterisk on all the micrographs illustrates the projection on the ventral side of the sinistroventral lip (character 42 ). Aspidodera scoleciformis (a); A. raillieti (b); P. uncinata (c); N. scapteromi (d); L. bolivari (e), and A. lacombae (f).

50 Extension of onchium relative to esophastome. The esophastome has three parts as well; however, these cuticular flanges originate from the esophagus (Figure 12). They lay immediately interior to each cheilorhabdion (cheilostome). The onchium is a projection that emerges from the basis of the esophastome. There may be two alternate states. Onchium exceeding the anterior-most margin of the esophastome, reaching the cheilostome (0), as in Heterakis; or onchium not exceeding the anterior margin of the esophasome (1) (see Figure 12).

51 Attachment of onchium to esophastome. Onchium attached to esophastome only at basis as in $A$. raillieti (Figure 12) (0); or onchium entirely fused with esophastome (see P. uncinata Figure 12) (1).

52 Anterior end of onchium. Anterior end of onchium may be blunt (0); or it may bear an acute projection (1) as in A. raillieti (Figure 12).

\section{Phylogenetic pattern}

The single shortest tree obtained from the analysis of morphological characters is presented in Figure 13 This tree is 128 steps long, $\mathrm{CI}=0.44, \mathrm{HI}=0.58$, $\mathrm{RI}=$ 0.73 and $\mathrm{R}=0.32$. This tree shows that species of Lauroia, Proencaia, Nematomystes and Paraspidodera, do not form a monophyletic group while species included in Lauroia are basal to the ingroup. In addition, Proencaia heterospiculata, the two known species of Nematomystes and Paraspidodera uncinata appear in three separate clades.

The analyses of the topologies enforcing the monophyly of the subfamilies Lauroiinae and Aspidoderinae and the monophyly of both Lauroia and Aspidodera resulted in longer cladograms (not shown) with lower consistency values than the tree shown in Figure 13. Enforcing the monophyly of the subfamilies results in a tree 148 steps long $(\mathrm{CI}=0.38, \mathrm{HI}=0.62$; $\mathrm{RC}=$ 0.65 ; $\mathrm{RC}=0.25)$; and enforcing the monophyly of Aspidodera and Lauroia, results in trees $145(\mathrm{CI}=0.4, \mathrm{HI}=$ 0.6 ; $\mathrm{RC}=0.68 ; \mathrm{RC}=0.27)$ and $134(\mathrm{CI}=0.43, \mathrm{HI}=0.57$; $\mathrm{RC}=0.72 ; \mathrm{RC}=0.31$ ) steps long, respectively.

Inspection of Table 2 allows us to identify several characters with low values of both consistency and rescaled consistency indexes. For example, the traits used to define the cordons, characters 7,8 and 9 show consistency indices of 0.25 each (Table 2). A similar situation occurs with some of the characters that describe the complexity of the lips (characters 6, 30, 32, $34,36,39,40$ and 42 ) with consistency indices of 0.5 or lower (Table 2). 

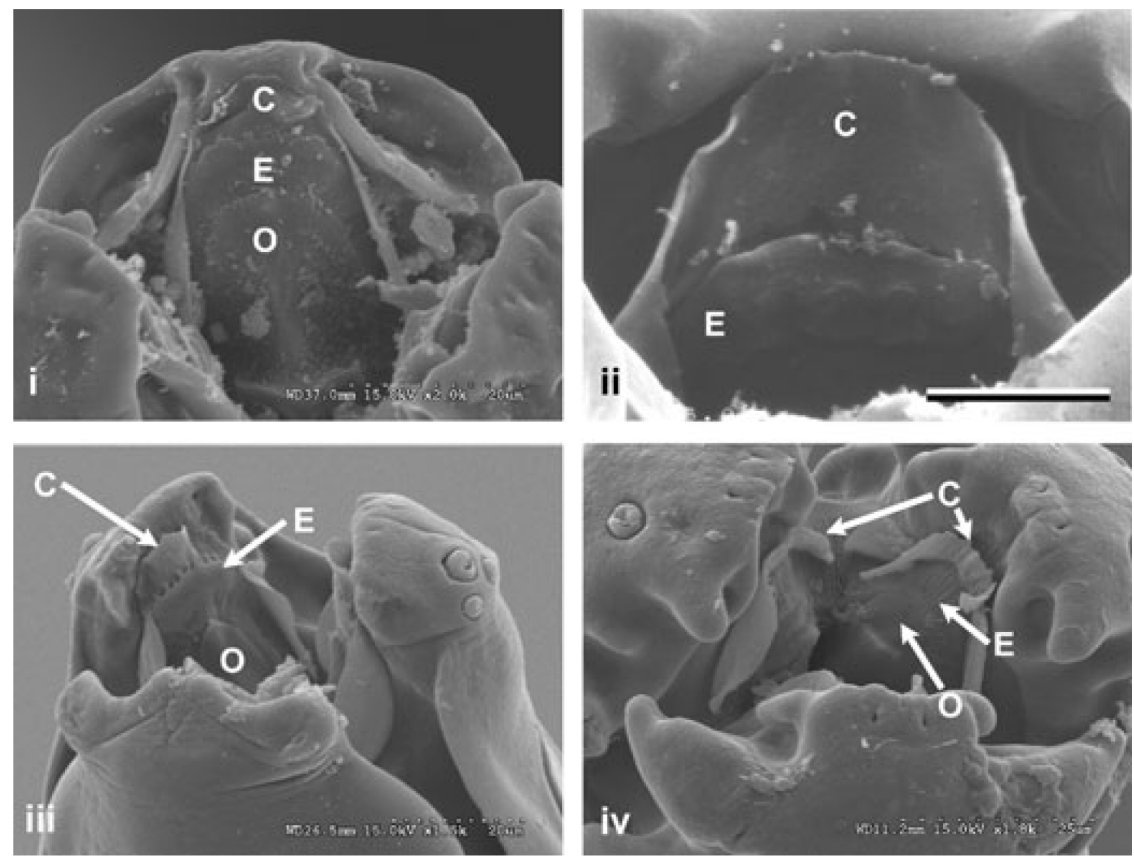

Figure 12. Structures of the stoma in Aspidoderidae. $\mathrm{C}=$ Cheilostome, $\mathrm{E}=$ Esophastome, $\mathrm{O}=$ Onchium. Note the fusion of onchium to cheilostome in "i" and "iv". Aspidodera vazi (i), A. sogandaresi (ii), A. raillieti (iii), P. uncinata (iv). Scale bar in ii $=5 \mu \mathrm{m}$.

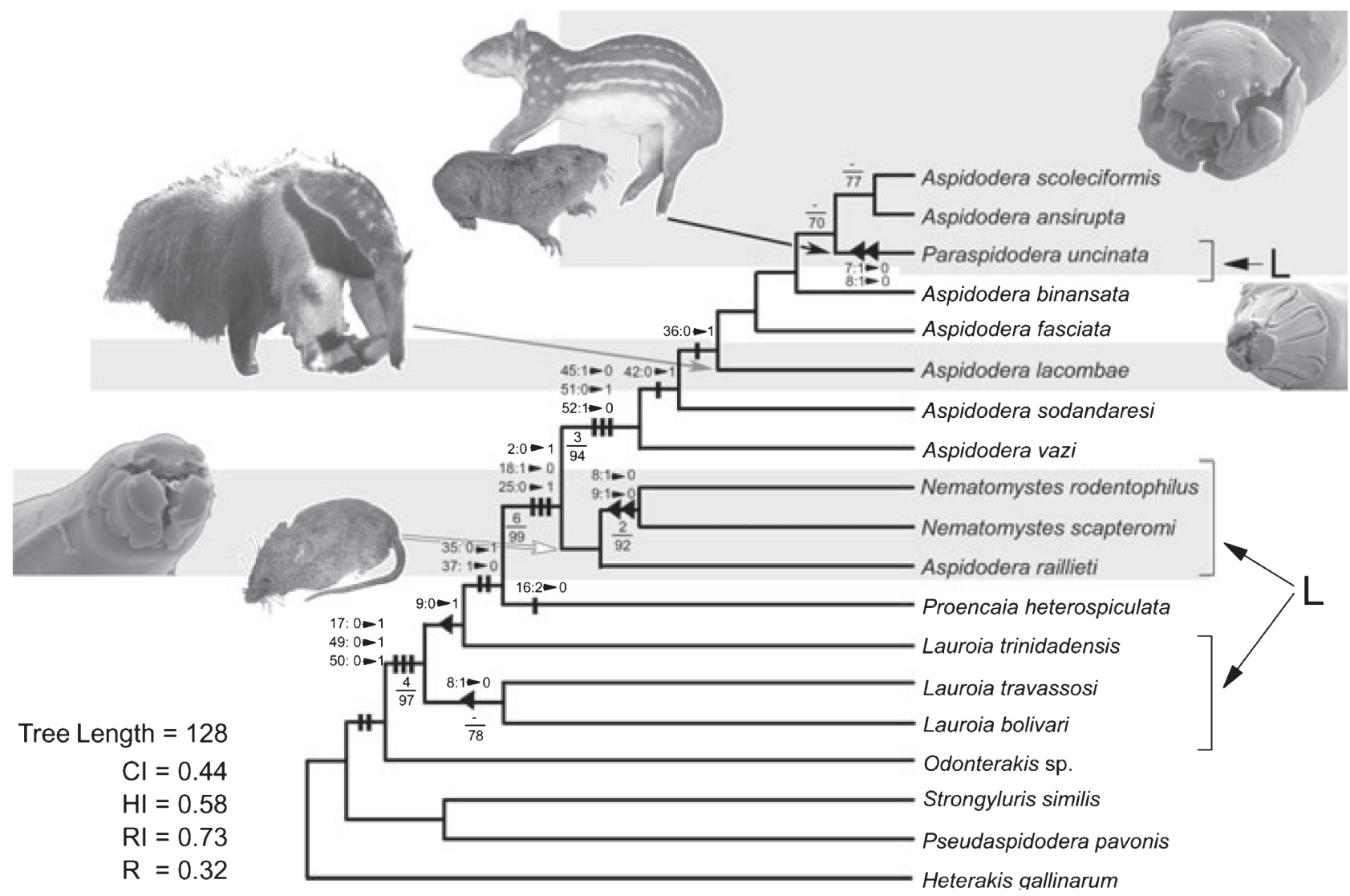

Figure 13. Shortest most parsimonious cladogram resulting from the analysis of the morphological characters of the Aspidoderidae. Three characters that traditionally served to define the "cordon" in the hood are mapped and represented with an inverted triangle (i.e., interlabium, 7; interlabial velum, 8; and labial grooves, 9). Unambiguous changes for indicated characters are represented with bold lines. Values for Bremer support/jackknife are shown below the clade they represent. Species classified in Lauroiinae are labeled with a "L". Arrows indicate host switching from armadillos to sigmodontine rodents (white) myrmecophagids (gray), and geomyd and cavid rodents (black). 
Table 2. Character diagnostics for the most parsimonious cladogram for members of Aspidoderidae. Characters in bold are chiefly involved in the diagnosis of Lauroiinae.

\begin{tabular}{|c|c|c|c|c|c|}
\hline Character & Min steps & Tree steps & Max steps & $\mathrm{CI}$ & RI \\
\hline 1 & 1 & 1 & 3 & 1 & 1 \\
\hline 2 & 1 & 1 & 8 & 1 & 1 \\
\hline 3 & 1 & 2 & 8 & 0.5 & 0.429 \\
\hline 4 & 1 & 2 & 8 & 0.5 & 0.429 \\
\hline 5 & 1 & 1 & 3 & 1 & 1 \\
\hline 6 & 1 & 2 & 9 & 0.5 & 0.438 \\
\hline 7 & 1 & 4 & 7 & 0.25 & 0.125 \\
\hline 8 & 1 & 4 & 6 & 0.25 & 0.1 \\
\hline 9 & 1 & 4 & 8 & 0.25 & 0.143 \\
\hline 10 & 1 & 3 & 4 & 0.333 & 0.111 \\
\hline 11 & 1 & 4 & 7 & 0.25 & 0.125 \\
\hline 12 & 2 & 6 & 11 & 0.333 & 0.185 \\
\hline 13 & 2 & 5 & 8 & 0.4 & 0.2 \\
\hline 14 & 1 & 2 & 3 & 0.5 & 0.25 \\
\hline 15 & 1 & 3 & 5 & 0.333 & 0.167 \\
\hline 16 & 2 & 4 & 4 & 0.5 & 0 \\
\hline 17 & 1 & 1 & 4 & 1 & 1 \\
\hline 18 & 1 & 1 & 8 & 1 & 1 \\
\hline 19 & 1 & 3 & 3 & 0.333 & 0 \\
\hline 20 & 1 & 2 & 7 & 0.5 & 0.417 \\
\hline 21 & 1 & 4 & 5 & 0.25 & 0.062 \\
\hline 22 & 1 & 2 & 5 & 0.5 & 0.375 \\
\hline 23 & 1 & 2 & 6 & 0.5 & 0.4 \\
\hline 24 & 1 & 3 & 4 & 0.333 & 0.111 \\
\hline 25 & 1 & 1 & 8 & 1 & 1 \\
\hline 26 & 1 & 3 & 4 & 0.333 & 0.111 \\
\hline 27 & 1 & 4 & 6 & 0.25 & 0.1 \\
\hline 28 & 1 & 5 & 8 & 0.2 & 0.086 \\
\hline 29 & 1 & 2 & 4 & 0.5 & 0.333 \\
\hline 30 & 2 & 5 & 7 & 0.4 & 0.16 \\
\hline 31 & 1 & 3 & 7 & 0.333 & 0.222 \\
\hline 32 & 1 & 2 & 8 & 0.5 & 0.429 \\
\hline 33 & 1 & 2 & 6 & 0.5 & 0.4 \\
\hline 34 & 1 & 3 & 8 & 0.333 & 0.238 \\
\hline 35 & 1 & 1 & 6 & 1 & 1 \\
\hline 36 & 1 & 1 & 6 & 1 & 1 \\
\hline 37 & 1 & 1 & 6 & 1 & 1 \\
\hline 38 & 1 & 4 & 8 & 0.25 & 0.143 \\
\hline 39 & 1 & 2 & 5 & 0.5 & 0.375 \\
\hline 40 & 1 & 2 & 7 & 0.5 & 0.417 \\
\hline 41 & 1 & 2 & 7 & 0.5 & 0.417 \\
\hline 42 & 1 & 1 & 7 & 1 & 1 \\
\hline 43 & 1 & 2 & 7 & 0.5 & 0.417 \\
\hline 44 & 1 & 2 & 4 & 0.5 & 0.333 \\
\hline 45 & 1 & 1 & 8 & 1 & 1 \\
\hline 46 & 1 & 2 & 5 & 0.5 & 0.375 \\
\hline 47 & 1 & 3 & 3 & 0.333 & 0 \\
\hline 48 & 1 & 4 & 8 & 0.25 & 0.143 \\
\hline 49 & 1 & 1 & 4 & 1 & 1 \\
\hline 50 & 1 & 1 & 4 & 1 & 1 \\
\hline 51 & 1 & 1 & 8 & 1 & 1 \\
\hline 52 & 1 & 1 & 8 & 1 & 1 \\
\hline
\end{tabular}

Based on our results, more reliable synapomorphies that define the family include the sessile caudal papillae, the relatively short cheilostome and the onchium embedded in the esophastome. As defined in the diagnosis of the family the presence of cuticle forming plates behind the lips, a groove, the dorsal papillae relative to the margins of dorsal lip, the proportions of the cheilostome relative to the lips and the short onchia may be used in combination to define the group. Additionally, the rim around the sucker combined with the grooves in the hood make Proencaia a valid genus. Finally, Nematomystes should be redefined so it includes Aspidodera raillieti. A proposed diagnosis for the family and these two genera is given below.

Aspidoderidae Skrjabin \& Shikhobalova, 1947. (Nemata: Heterakoidea, Type species Aspidodera scoleciformis Railliet \& Henry, 1912). Structures of anterior end of body forming plates derived from the expansion of cuticle behind lips. Plates offset from body. Plates separated from body by a space in the form of a groove, well defined in interlabial areas. Papillae on dorsal lip at the basis of digitiform projections. Cheilostome included in the margins of lips. Onchia relatively short, not exceeding the margins of esophastome. Males with precloacal sucker, tail of females tapering gradually posteriad; cuticle in the tail of males forming a loose cuticular spine or spinneret.

Lauroia Proença, 1938. (Type species Lauroia travassosi Proença, 1938). Anterior plates with cuticular flanges around the edges or restricted to the posterior corners; plates separated by a space without any emerging cuticular projections; smooth precloacal papillae and medial postcloacal protuberance; three pairs of caudal papillae in males aligned into two subventral parallel lines.

Proencaia Gomes \& Pereira, 1970. (Type species Proencaia heterospiculata Gomes \& Pereira, 1970). Cephalic plates with continuous velum around lateral and posterior margins, groove separating plates from body, interlabium developed as a cuticular ridge at base of plates; small cuticular rim surrounding precloacal sucker.

Nematomystes Sutton, Durette-Desset and Chabaud, 1980. (Type species Nematomystes rodentophilus Sutton, Chabaud \& Durette-Desset, 1980). Trapezoidal labial plates in anterior end; velum arising from each posterior corner. Conspicuous digitiform projection of interlabium with a fosset-like papillae on top. Amphid closer to dorsal margin of lateroventral lips, aligned with two papillae. Onchium united to esophastome only at the basis. Esophagus with elongated bulb. Sucker surrounded by a cuticular rim.

Aspidodera Railliet \& Henry, 1912. (Type species Aspidoderascoleciformis Railliet\&Henry,1912). Dorsalcorners of lateroventral lips expanded. Dorsal lip with prominent digitiform structures projected laterally. Onchium fused to esophastome, presenting blunt anterior end. 
Paraspidodera Travassos, 1914. (Paraspidodera uncinata (Travassos,1914)).Shorthood, withnoextended grooves; no interlabial projection present. Square-shaped plates, velum restricted to the posterior corners of the plate.

\section{Discussion}

Our analysis shows that the Lauroiinae is not monophyletic and the characters used to diagnose the taxa in the family are not simple. Figure 13 shows that the genera Lauroia, Nematomystes and Paraspidodera do not share a single common ancestor and the Lauroiinae is therefore paraphyletic. Additionally, the overall shape of the anterior end of the body of these nematodes is in fact determined by the combination of up to 12 characters. For example, the plate-like structures and the round lips present in species of Lauroia and Nematomystes may be determined by the limited grooves and short digitiform projections in the lips.

\section{Character mapping}

Several of the morphological characters that have been used in the diagnosis of some genera were demonstrated herein to be homoplasious in nature. For example, a combination of four characters define the cordons. The combination of the character states of those characters (groove, velum -2-, and interlabial projections) may converge in an overall appearance of plates in the anterior end of these worms. That is the case of the similarity in the plate-like structures in the hood of Paraspidodera uncinata, Proencaia heterospiculata, and species of Nematomystes and Lauroia. On the tree in Figure 13, the relative positions of Paraspidodera uncinata, Proencaia heterospiculata and species of Lauroia lead us to conclude that the similarity of the plates in the hood are just that and are not evolutionary homologs. Therefore, these characters should not be used in the diagnosis of the subfamily (Chabaud, 1978; Sutton et al., 1980).

In light of the phylogenetic hypothesis and the characters mapped in Figure 13, the character "recurrent cordons in the hood", which was used to define the species in the genus Aspidodera, is shown to be homoplasious and may be the result of a convergence in the feeding habits of these nematodes. An example from some distantly related taxa in the same superfamily that converge in these structures are species of PseudAspidodera, but these species lack the characters that define the family (i.e., sessile papillae, structure of cheilostome, esophastome and onchium, and postcloacal subcuticular papillae or "bump" seen in males).

\section{Taxonomic remarks}

Our results stand in opposition to the classification of Inglis (1967) and Chabaud (1978) as we show that the subfamilies Aspidoderinae (which contains only species in the genus Aspidodera) and Lauroiinae (which currently contains species of Lauroia, Paraspidodera and Nematomystes) are not natural groups. The topological form of the tree also indicates that the presence or absence of cordons does not warrant placing these species into separate groups as established by Inglis $(1957 a, b)$. This is due to the low value of the consistency index of these characters (8-11, see Table 2), which are part of the cordon, as defined by Inglis (1957b) (see Figure 13).

Our analysis shows that Lauroia is defined by a simple sucker with no cuticular rim, a postcloacal posterior bump, and genital papillae arranged in two parallel lines. However the Lauroiinae as defined by Chabaud (1978) is not monophyletic. The causes may be the different character states for the grooves and the hood that are different in L. trinidadensis when compared with both L. travassosi and L. bolivari. The former may have in Lauroia intermedia Caballero (1955) putative sister species because they share the same character states for all structures. However, L. intermedia was excluded from our analysis because the diagnostic character that makes it conspicuously different from L. trinidadensis is a single autapomorphy [a spine in the ventral side of the body that appears between the lateroventral plates (Caballero 1955)]. The low support for the clade (L. bolivari, L. travassosi) and L. intermedia, suggests that most of the characters supporting those branches are homoplasious; seen clearly as reversals of the character states for the groove and velum (characters 8 and 9 as mapped on Figure 13).

In addition, Figure 13 shows the sister clade of Lauroia (Proencaia + Nematomystes + Aspidodera + Paraspidodera) is defined by the presence of the following: a square-shaped dorsal lip, a pronounced digitiform projection on the ventral side of the sinistroventral lip, and a cuticular rim that surrounds the precloacal sucker in the males (characters 35, 37; Figure 13). However, because of reasons similar to those discussed for Lauroia this group does not have strong support in our analysis. In contrast, the clade including Nematomystes + Aspidodera + Paraspidodera has stronger support. An explanation is found in the number of unambiguous changes for the members of those clades, and in the following characters: spicule structure, caudal ornamentation of males, and the hood that is common to these species.

Finally, Aspidodera raillieti is shown to be the sister taxon of the species recognized herein as the genus Nematomystes. Based on our results we hereby transfer A. raillieti to the genus Nematomystes giving the new combination the form: Nematomystes raillieti (Travassos 1914). The characters supporting this inclusion are the papillae on the lateroventral lips grouped towards the dorsal margin of the lip, and the papillae at the 
tips of each interlabium. This clade is shown to have a moderate amount of support, due perhaps to the homoplasy in the structure of the groove.

To retain as valid the subfamilies proposed by previous authors, the diagnosis for each group would need emendation; however, there is no unambiguous synapomorphy for any of these taxa. This is revealed when the monophyly of the subfamilies (not shown) is enforced as a constraint tree. The comparison of this constrained tree results in a cladogram at least 20 steps worse than the one shown in Figure 13 (T-PTP $P=0.002$ ).

\section{Problematic taxa}

The resulting topological configuration seen in our analysis is inconsistent with the current taxonomy of the group. Our analysis shows that species included in the genus Lauroia have no un-reversed synapomorphies and this genus is defined only by reversals in the character states of the rim around the precloacal sucker and the arrangement of the precloacal papillae in two parallel rows (Figure 13). Mapping of characters on the shortest tree shows that the continuous groove in L. trinidadensis makes this species very different from the rest of the species in the genus. To evaluate this problem we performed a constraint analysis and forced the data on to the tree with Lauroia held as a monophyletic group. The branch and bound search resulted in two trees, each, six steps longer than the original unconstrained tree. However, the Bremer support values for the clade, including all species of Lauroia equals zero. Therefore, at the present time, and even though the genus appears to be polyphyletic, we do not propose to modify the diagnosis of, or species included in the genus Lauroia. Application of a molecular data set may enable a resolution of this question more completely at a later date.

Except for an earlier enlightened proposal by Chabaud (1957) the inclusion of $P$. uncinata in a clade with species of Aspidodera was not predicted by any of the current classifications (Freitas, 1956; Inglis, 1957a; Chabaud, 1978) see Figure 13. This is because, in the current classification, the structures in the body of worms of both Paraspidodera and Aspidodera (Chabaud, 1957; Inglis, 1967) were overridden by perceived greater importance of the absence of interlabia in Paraspidodera. The grouping (A. vazi (A. sogandaresi (A. lacombae (A. fasciata (A. binansata (Paraspidodera uncinata (A. ansirupta (A. scoleciformis)))))))) is also well supported by a Bremer support value of 3 (Figure 13). Even though there seems to be evidence to consider Paraspidodera a junior synonym of Aspidodera, we opted to maintain Paraspidodera as a valid genus name. In this case a similar logic was followed with respect to the genus Lauroia, which does not appear to be monophyletic.
So the splitting of Lauroia into two genera and the merging of Paraspidodera and Aspidodera into a single taxon cannot be executed with a high level of confidence. Doing so would introduce more problems to the taxonomy and stability of the group than would be solved. In this analysis, neither jackknifing nor decay indices were used as statistical tools to reject or accept hypotheses of existence of internal clades. Rather, we rely on these values as parameters that provide a measure of the robustness of those groupings in contrast to the current taxonomy. In both cases, support for clades that challenge the current taxonomic groups is weak; thus our position is to maintain unaltered, the taxa involved (i.e., Paraspidodera, Aspidodera, and Lauroia). Recently, Ramírez (2005) provided some justification for this as he invoked the stability of the taxonomy over proposing new names and groupings based on a weakly supported topology. The case of the genera Paraspidodera, Aspidodera and Lauroia illustrates that point. The proposal of an amended diagnosis and new generic names would be based on groupings with low support and no clear apomorphies.

\section{Distribution of parasites in their hosts}

Groups of mammals infected by aspidoderids is shown in Table 3. Presence of species of parasite is recorded as occurring in one of the six families that are known to serve as hosts to these nematodes. We considered the host of Proencaia heterospiculata as unknown, because heterakoid nematodes are not common parasites of carnivores. It appears that the presence of only one individual nematode in a felid may be the result of an accidental infection, as the parasite may have remained alive in the cat for some time after her meal.

The distribution of hosts on the tree of the parasites was optimized with the program DIVA1.1 (Ronquist, 1996), which minimizes the number of extinction and host-switching events. We analyzed each of the groups of hosts as potentially infected by $P$. heterospiculata in a search for an optimal estimation of the ancestral hosts for the nodes and terminal clades. The only combination that a priori seems unlikely is $P$. heterospiculata infecting a member of the family Geomyidae, as neither parasite nor host occur (or have occurred) in the same biogeographical area. The Geomyidae are restricted to the Nearctic and northern Neotropical regions, with little evidence that these rodents have penetrated further than extreme northern Colombia (Eisenberg, 1989). The optimal reconstruction with fewer dispersal or host switching events (nine in this case) supposes that the host for $P$. heterospiculata should be a member of the family Dasypodidae. The reconstructions using any other host requires 10 dispersal events. The estimate that all the groups of mammals listed above (except the 
Table 3. Summary of the distribution of species in their hosts. The hosts have been entered as taxonomical units of higher hierarchies at the family level. Note that Proencaia heterospiculata was originally recorded in a felid; however, we have recorded it as a parasite of Dasypodidae.

\begin{tabular}{l|llllll} 
& Dasypodidae & Myrmecophagidae & Didelphidae & Caviidae & Sigmodontinae & Geomyidae \\
\hline Lauroia travassosi & 1 & 0 & 0 & 0 & 0 & 0 \\
Lauroia bolivari & 1 & 0 & 0 & 0 & 0 & 0 \\
Lauroia trinidadensis & 1 & 0 & 0 & 0 & $?$ & 0 \\
Proencaia heterospiculata & $?$ & $?$ & $?$ & 0 & 1 & 0 \\
Paraspidodera uncinata & 0 & 0 & 0 & 0 & 1 & 1 \\
Nematomystes rodentophilus & 0 & 0 & 0 & 0 & 1 & 0 \\
Nematomystes scapteromi & 0 & 0 & 1 & 0 & 0 & 0 \\
A. raillieti & 0 & 0 & 1 & 0 & 0 \\
A. binansata & 1 & 0 & 0 & 0 & 0 \\
A. fasciata & 1 & 1 & 0 & 0 & 0 \\
A. vazi & 1 & 0 & 0 & 0 & 0 \\
A. lacombae & 0 & 1 & 0 & 0 & 0 \\
Aspidodera scoleciformis & 1 & 1 & 0 & 0 & 0 \\
A. ansirupta & 1 & 0 & 0 & 0 & 0 \\
A. sogandaresi & 1 & 0 & 0 & 0
\end{tabular}

Geomyidae) may serve as hosts for this parasite assumes 12 dispersal events. We prefer the first scenario, as it implies fewer (nine) events and does not require proposed extinctions events.

The optimal reconstruction (not shown) allows us to identify three events of host switching assuming Dasypodidae (the armadillos) as ancestral hosts. One event shows a switch of the ancestor of $P$. uncinata to the Caviidae (the cavy-like rodents of South America) and the Geomyidae (pocket gophers primarily in the Nearctic, black arrow in Figure 13). The second event shows a switch of the ancestor of A. lacombae to neotropical ant-eaters (Myrmecophagidae, gray arrow in Figure 13). The third event shows that the ancestor of the three species of Nematomystes host switching to Didelphidae (opossums in both the Nearctic and Neotropical regions and the Sigmodontinae (Rodentia: Muridae: Sigmodontinae, white arrow in Figure 13).

The inclusion of additional characters derived from molecules would be very useful in helping us to understand the complex phylogenetic and biogeographical relationships among members of the family Aspidoderidae. For progress to be made in both systematics and biological diversity research in the group, a robust phylogenetic hypothesis of these nematodes is necessary as it will enable researchers to propose solid classifications and will also enable a more firm understanding of their historical ecology, biogeography and coevolutionary relationships.

\section{Acknowledgments}

This work was supported by National Science Foundation grants BSR-8612329, BSR-9024816, DEB-9496263, DEB-9631295, DBI-0097019 to S.L.G. and CNPq
300067/2005-4 to R.M.P. We thank Cristina Damborenea (CHLP), Sumiya Ganzorig (CPSVM), Luis García (CNHE), Eric Hoberg (USNPC), Luis Muniz (CHIOC), Graciela Navone (CEPAVE), Judith Price (CMN), Lidia Sánchez and Elizabeth Morales (CHSM) for sending to us the material that they have under their care. Berenit Mendoza and Kit Lee assisted in the imaging of specimens in SEM. David Tinnin for his critical comments on earlier versions of the manuscript. Support was provided to F.A.J.R. by CONACyT-México in form of a scholarship, the Walker Graduate Student Funds and the Initiative in Ecology and Evolutionary Ecology both granted by the School of Biological Sciences of UNL.

\section{References}

Bremer, K., 1988. The limits of amino acid sequence data in angiosperm phylogenetic reconstruction. Evolution 42, 795-803.

Caballero, E., 1955. Estudios helmintologicos de la región oncocercosa de México y de la república de Guatemala. Nematoda. 9a. Parte. Acta Zool. Mex. 1, 1-5.

Chabaud, A.G., 1957. Sur la systématique des nématodes du sous-ordre des Ascaridina parasites des vertébratés. Bull. Soc. Zool. Fr. 82, 243-253.

Chabaud, A.G., 1978. CIH Keys to the Nematode Parasites of Vertebrates, No. 6. Keys to genera of the Superfamilies Cosmocercoidea, Seuratoidea, Heterakoidea and Subuluroidea. Commonwealth Agricultural Bureaux International, Farnham Royal, UK.

Eisenberg, J.F., 1989. Mammals of the Neotropics: the Northern Neotropics, Vol. 1. Panama, Colombia, Venezuela, Guyana, Suriname, French Guiana. University of Chicago Press, Chicago, IL.

Freitas, J.F.T., 1956. Notas sôbre 'Heterakidae' Railliet \& Henry, 1914 (Nematoda, Subuluroidea). Rev. Bras. Biol. 16, 461-482.

Inglis, W.G., 1957a. A review of the nematode superfamily Heterakoidea. Ann. Mag. Nat. Hist. Zool. Bot. Geol. 12, 905-912.

Inglis, W.G., 1957b. The comparative anatomy and systematic significance of the head in the nematode family Heterakidae. Proc. Zool. Soc. London, 128, 133-143. 
Inglis, W.G., 1967. The evolution, host relationships and classification of the nematode superfamily Heterakoidea. Bull. Br. Mus. (Nat. Hist.), 15, 3-28.

Inglis, W.G., 1991. A revision of the nematode genus Odontoterakis Skrjabin \& Schikhobalova, 1947 (Heterakoidea). Syst. Parasitol. 20, 60-79.

Inglis, W.G., Schmidt, G.D., Kuntz, R.E., 1971. Nematode parasites of Oceanica. XII. A review of Heterakis species, particularly from birds of Taiwan and Palawan. Rec. S. Aust. Mus. $16,1-14$.

Platnick, N.I., 1979. Philosophy and the transformation of cladistics. Syst. Zool. 28, 537-546.

Proença, M.C., 1937. Revisão do gênero Aspidodera Railliet and Henry, 1912. Mem. Inst. Oswaldo Cruz, 32, 427-438.

Ramírez, M.J., 2005. Resampling measures of group support: a reply to Grant and Kluge. Cladistics 21, 83-89.

Ronquist, F., 1996. DIVA, Version 1.1. Computer Program and Manual. Available by Anonymous FTP from Uppsala University (ftp:uu.se or ftp:systbot.uu.se).

Santos, C.P., Lent, H., Gomes, D.C., 1990. The genus Aspidodera Railliet and Henry, 1912 (Nematoda: Heterakoidea): revision, new synonyms and key for species. Rev. Bras. Biol. 50, 1017-1031.

Skrjabin, K.I., Shikhobalova, N.P., Lagodovskaya, E.A., 1961. Osnovy nematodologii Tom X. Oksiurati shivotnykh i cheloveka. Chast 2. Izdatel'stvo Akademiya Nauk SSSR, Moskva.

Sorenson, M.D., 1999. TreeRot, Version 2c. Boston University.

Sutton, C.A., Chabaud, A.G., Durette-Desset, M.C., 1980. Contribución al conocimiento de la fauna parasitológica Argentina. VI. Sobre un nuevo Lauroiinae (Nematoda, Ascaridida). Bull. Mus. Nat. Hist. Nat. A Zool. Biol. Écol. Anim. 2, 81-85.

Swofford, D.L., 2003. PAUP*. Phylogenetic Analysis Using Parsimony ( ${ }^{*}$ and Other Methods), Version 4, Version Beta 10. Sinauer Associates, Sunderland, MA.

Vicente, J.J., 1966. Revisão da subfamília Aspidoderinae Skrjabin \& Shikhobalova, 1947 (Nematoda). Mem. Inst. Oswaldo Cruz 64, 131-161.

Vicente, J.J., Rodrigues, H.O., Gomes, D.C., Pinto, R.M., 1997. Nematóides do Brasil. Parte V: Nematóides de Mamíferos. Rev. Bras. Zool. 14, 1-452.

\section{Appendix}

Specimens examined were borrowed from and deposited into the following collections: Colección Helmintologica do Instituto Oswaldo Cruz (CHIOC), Rio de Janeiro, Brazil; Canadian Museum of Nature (CMNN); Colección Nacional de Helmintos (CNHE), Mexico City, Mexico; Colección Helmintológica y de Invertebrados Afines del Museo de Historia Natural de la Universidad Nacional San Marcos (CHSM); Colección Helmintológica del Museo de la Universidad Nacional de la Plata (CHLP); Collection of Parasitology of the School of Veterinary Medicine of the University of Hokkaido (PCVS), Sapporo, Japan, and the United States National Parasite Collection (USNPC), Beltsville, Maryland. The Holotype is indicated in bold.

Lauroia travassosi Proença, 1938

CHIOC: 9637, 9638, 9644, 9712, 18357, 32352, 34565.

Lauroia bolivari Jiménez-Ruiz and Gardner, 2003

HWML: 16948, 16949, 16950, 16951, 16952.
L. intermedia Caballero, 1955

CNHE: 2460.

Lauroia trinidadensis Cameron, 1937 (Junior synonym:

Lauroia dasypi Flores-Barroeta-1956)

HWML: 48193 48194, 48195, 48244. CNHE: 5366.

Proencaia heterospiculata Gomes and Pereira, 1970 (Monotypic)

CHIOC: 30527.

Nematomystes rodentophilus Sutton, Durette-Desset and Chabaud, 1980

CHLP: 180. HWML: 16944, 16945, 16946, 16947, 16959, 16960. CHSM: 14404.

Nematomystes scapteromi (Ganzorig, Oku, Malgor and Kamiya, 1999) (Synonym Ansiruptodera scapteromi)

CHLP: 2184, PCVS: 2984, 2985. NP369, NP371, NP375, NP377, NP380, NP381, NP385, NP386, NP387, NP388, NP340.

Nematomystes raillieti (Travassos, 1914) (Synonyms Aspidodera raillieti, Aspidodera harwoodi Chandler, 1932, Aspidodera vicentei Pinto, Kohn, Fernandes and Mello, 1981, Aspidodera diaz-ungriai Masí-Pallarés and Benítez-Uscher, 1971)

CHIOC: 12, 92, 93, 100, 132, 290, 444, 760, 1011, 2644, 2768, $5338,5342,6017,6664,6670,6671,6672,6673,7459,7591$, $7602,8423,9261,9640$ 13648, 14065, 14075, 14060, 17739, 17736, 18356, 19115, 19290, 29931, 30097, 30098, 31305, $31915,31970,32353,32354,32493,33498,33545,33546$, $33549,33554,33556,33558,33563,33565,33579,33583$, 33567, 33569, 7891, 9630, 7448. CMNA: 408. CNHE: 2110. CHSM: 6058, 14336, 14345, 14382, 15987, 15989. USNPC: 8550, 17959.

Aspidodera scoleciformis (Diesing, 1851)

CHIOC: 10, 706, 707, 710, 5681, 5809, 8387, 9668, 11408, 14551, 15073, 15257, 19494, 20046, 29928, 34557, 34568. PCVS: 2951.

Aspidodera ansirupta Proença, 1937 (Synonym Ansiruptodera ansirupta)

CHIOC: 7363, 9637, 9638, 29934,

Aspidodera fasciata (Schneider, 1866)

CHIOC: 11, 98, 709; 4119, 4446, 5681, 5810, 7392, 7910, 8387, 9638, 11190, 11408, 11764, 13057, 13058, 13088; $14408,14442,14465,15074,15257,15938,18352,18353$, 19494, 19628, 20046, 20066, 29930, 30729, 33635, 34558, 34567. PCVS: 2950. USNPC: 17957, 59968.

Aspidodera binansata Railliet and Henry, 1913 (Synonym Aspidodera esperanzae Fujita, Abe, Oku, Inchausti and Kamiya, 1995)

CHIOC: 8260, 9637, 9639, 9643, 14082, 18351, 18355, 29933, 34559, 34561, 34562, 34563, 34566. CMNA: 960. PCVS: 2955, 2960. HWML: 16953, 16954, 16962, 16963, 16964.

Aspidodera vazi Proença, 1937

CHIOC: 4446, 9638, 9641, 9644, 11193, 14086, 18354, 18355, 29932, 34564. HWML: 48192.

Aspidodera lacombae Vicente, 1964

CHIOC: 29778, 29779, 30117, 34288. 
Aspidodera sogandaresi Jiménez-Ruiz, Gardner and Varela-Stokes, 2006

CHIOC: 35430. CMNPA: 2005-0023, 2005-0024. CNHE: 5359, 5360, 5361, 5362. HWML: 48179, 48180, 48181, 48182, 48183, 48184, 48185, 48186, 48187, 48190, 48489, 48243. 35429, 35431. USNPC: 97132, 97133.

Paraspidodera uncinata Travassos, 1914 (Synonyms Paraspidodera uruguaya, Khalil, 1931, Paraspidodera amer- icana Khalil, 1931)

CHIOC: 14, 811, 1706, 1740, 1824, 2045, 2046, 2392, 4449, 4630, 5665, 7526, 8548, 9949, 9859, 9956, 11758, 16620, 16930, 16935, 17767, 18905, 18906, 18907, 18908, 19307, 21172, 27012, 29946, 30083, 30106, 30107, 30108, 30109, 30110, 30134, 31893, 31974. CHLP: 38. CNHE: 2190, 2287. 